\title{
Immunotherapy Targeting Tumor-Associated Macrophages
}

\author{
Yafei Liu ${ }^{1 *}$ and Rongsi Wang ${ }^{2}$ \\ ${ }^{1}$ Department of Pharmacy, The Forth Affiliation Hospital of China Medical University, Shenyang, China, ${ }^{2}$ High School of East \\ China Normal University, Shanghai, China
}

Macrophages are phagocytic cells that play a broad role in maintaining body homeostasis and defense against foreign pathogens; whereas tumor-associated macrophages (TAMs) support tumor growth and metastasis by promoting cancer cell proliferation and invasion, immunosuppression, and angiogenesis, which is closely related to the poor prognosis in almost all solid tumors. Hence, deep-insight knowledge into TAMs can provide an opportunity to discover more effective strategies for cancer therapeutics. So far, a large number of therapeutic agents targeting TAMs are in clinical trials. In this review, we introduce an extensive overview about macrophages and macrophage-targeting agents.

Keywords: macrophage, tumor microenvironment, cancer, immunotherapy, polarization

\section{OPEN ACCESS}

Edited by:

Weien Yuan,

Shanghai Jiao Tong University, China

Reviewed by:

Irina V. Larionova

Tomsk State University, Russia

Jian Zhong,

Shanghai Ocean University, China

Chong Li,

Southwest University, China

*Correspondence:

Yafei Liu

xiaoxiang0618@163.com

Specialty section:

This article was submitted to

Translational Medicine,

a section of the journal

Frontiers in Medicine

Received: 15 July 2020 Accepted: 23 September 2020 Published: 05 November 2020

Citation:

Liu Y and Wang R (2020) Immunotherapy Targeting

Tumor-Associated Macrophages.

Front. Med. 7:583708.

doi: 10.3389/fmed.2020.583708

\section{INTRODUCTION}

Cancer, a global public health problem, is the first or second leading cause of death in most countries, and its incidence and mortality are rapidly growing (1). Clinically it is well-acknowledged that tumor sites contain not only cancer cells, but also immune cells, including macrophages, regulatory $\mathrm{T}\left(\mathrm{T}_{\text {reg }}\right)$ cells (2), neutrophils (3), mast cells (4), natural killer (NK) cells (5), etc. Macrophages, the main component of the mononuclear phagocyte system (6), are phagocytic cells which play a broad role in maintaining body homeostasis and defense against foreign pathogens; whereas there are a large number of TAMs in tumor microenvironment (TME), which support tumor growth and metastasis by promoting cancer cells proliferation, immunosuppression, invasion, and angiogenesis. Therefore, scientists pay special attention to TAMs when looking for effective cancer treatment strategies. In recent decades, several types of immunotherapies targeting TAMs are playing more and more important roles in the treatment of cancer.

This comprehensive review first summarizes most recent updates regarding macrophage recruitments and functions in tumor, then focuses on the development and evaluation of cancer immunotherapy strategies targeting TAMs including drugs in pre-clinical and clinical stages. Finally, we would like to provide some views and visions of immunotherapy targeting TAMs.

\section{ORIGINS AND POLARIZATION OF MACROPHAGES}

Macrophages were first discovered and isolated by Ilya Metchnikoff in the nineteenth century (7). For decades, most people thought that blood-circulating monocytes derived from adult bone marrow (BM) continuously repopulate tissue-resident macrophages (TRMs). It is now wellaccepted that a large number of TRMs derive from embryonic precursors, which are from both fetal yolk sac and fetal liver progenitors (8-12). All precursors seed different tissue and differentiate into specialized TRMs on the basis of tissue-specific context $(10,13)$. Moreover, most tissues also contain macrophages derived from monocytes after birth (13-15). However, some tissues are different, such that monocytes derived from hematopoietic stem cells (HSCs) fleetly take the place 
of embryonic macrophages after birth in the colon, but microglia are rarely from monocytes derived from HSCs under homeostatic conditions $(16,17)$ (Figure 1A). In tumors, TAMs are usually thought to primarily derive from circulating monocytes, and most recent studies have shown that functions and phenotypes of embryonic-derived and monocyte-derived macrophages are different $(13,18,19)$. For example, Pierre-Louis Loyher et al. showed that embryonic-derived TAMs largely correlated with tumor cell growth in vivo, while monocyte-derived TAMs accumulation was associated with enhanced tumor spreading (18). Furthermore, several studies have suggested that TRMs are up to $50 \%$ in some murine models such as lung and brain cancer $(18,20)$.

Macrophages are a type of remarkable plastic cells and can be easily induced by surrounding microenvironment $(21,22)$. According to different activation methods, macrophages are divided into two extremes (23), Classically activated macrophages (M1 macrophages) and alternatively activated macrophages (M2 macrophages). M1 and M2 macrophages have significant differences in surface receptor expression, tissue distribution, metabolism, cytokine and chemokine production, function, and intracellular signal transduction. M1 macrophages are polarized by lipopolysaccharide (LPS), which binds to the Toll-like receptor 4 (TLR4). Then an inflammatory response is elicited (24), and pro-inflammatory cytokines are released, such as interleukin-1 $\beta$ (IL-1 $\beta$ ), IL-6, and tumor necrosis factor- $\alpha$ (TNF$\alpha$ ). These downstream signals recruit more macrophages to resist pathogenic insult (25). M2 macrophages are polarized by cytokines such as IL-4 and IL-13, and release anti-inflammatory cytokines including transforming growth factor- $\beta$ (TGF- $\beta$ ) and IL-10, inducing processes like membrane remodeling and angiogenesis to promote tissue repair $(26,27)$. Depending on specific inducing signals and their biological roles, M2 macrophages could be further divided into M2a, M2b, M2c, and M2d (28-32) (Figure 1B). Generally speaking, M1 macrophages mainly kill and clear cancer cells $(33,34)$, while M2 macrophages mainly support tumor development $(35,36)$. This M1/M2 concept can easily explain macrophage heterogeneity, but it is too simple to explain the complexity of macrophage activation. Actually, TAMs seem to consist of various populations with a wide range of polarization features or activation states, and their

Abbreviations: AMT, adoptive macrophages transfer; Arg-1, arginase-1; BM, bone marrow; BTK, Bruton's tyrosine kinase; CAR-M, chimeric antigen receptor macrophage; CAR-T, chimeric antigen receptor $\mathrm{T}$ cells; CCL, CC chemokine ligand; CCR, CC chemokine receptor; CSF-1R, CSF-1 receptor; CXCL8, CXC chemokine ligand 8; ECM, extracellular matrix; FLT1, FMS-like tyrosine kinase 1 ; HIF $1 \alpha$, hypoxia-inducible factor $1 \alpha$; HSCs, hematopoietic stem cells; IFN- $\gamma$, interferon- $\gamma$; iNOS, inducible nitric oxide; Jak2, Janus kinase 2 ; IL-1 $\beta$, interleukin- $1 \beta$; LPS, lipopolysaccharide; MAMs, metastasis-associated macrophages; M-CSF/CSF-1, macrophage-colony stimulating factor; MHC II, major histocompatibility complex class II; MPS, mononuclear phagocyte system;

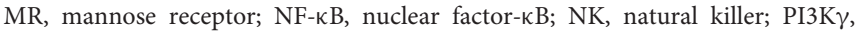
PI-3 kinase $\gamma$; PMN, pre-metastatic niche; $\operatorname{SIRP} \alpha$, signal regulatory protein $\alpha$; $\mathrm{SR}$, scavenger receptor; STAT3, signal transducer and activator of transcription 3 ; TAMs, tumor-associated macrophages; TGF- $\beta$, transforming growth factor$\beta$; $\mathrm{T}_{\mathrm{H}}$ 2, T helper 2; TIE-2, tumor endothelium releases angiopoietin-2; TLR4, Toll-like receptor 4; $\mathrm{T}_{\text {reg, }}$, regulatory $\mathrm{T}$; TRMs, tissue-resident macrophages; TME, tumor microenvironment; TNF- $\alpha$, tumor necrosis factor- $\alpha$; VEGF, vascular endothelial growth factor. function is determined by microenvironment. Hence, additional studies are necessary to better classify macrophages, and there are several articles about other classifications (37-39).

\section{FUNCTIONS OF MACROPHAGES IN TME}

\section{Promoting Tumorigenesis and Progression}

TAMs are believed to be the bridge between cancer and inflammation. Some studies show that about $25 \%$ of all cancers are related to chronic infection and inflammation (40). The production of chemokines and cytokines are induced by key transcription factors [such as nuclear factor- $\kappa \mathrm{B}(\mathrm{NF}-\kappa \mathrm{B})$ ], hypoxia-inducible factor $1 \alpha(\mathrm{HIF} 1 \alpha)$, and signal transducer and activator of transcription 3 (STAT3) when chronic inflammation occurs, which activates the innate immune system and especially macrophages (41). There is a lot of evidence that the inflammatory microenvironment promotes genetic instability of tumor epithelial cells and tumor-infiltrating immune cells $(42,43)$. Recently, the inflammatory cytokines IL-23 and IL17 secreted by TAMs have been shown to be closely related to human colorectal cancer progression (44). For instance, Kupffer cells can promote the progression of hepatocellular carcinoma by secreting mitogens, which relies on the NF- $\kappa \mathrm{B}$ signaling pathway (45). Other results show that IL- 6 produced by TAMs promotes the development of liver cancer through STAT3 signaling pathway (46), and IL-10 produced by TAMs promotes the development of non-small cell lung cancer through STAT1 signaling (47).

\section{Formation of the Immunosuppressive Microenvironment}

Macrophages cannot only kill tumor cells directly when they are activated by interferon- $\gamma$ (IFN- $\gamma$ ), but also recruit and activate $\mathrm{CD}^{+}$cytotoxic $\mathrm{T}$ lymphocytes and NK cells by presenting antigens and secreting cytokines to promote the adaptive immunity (48). In addition, $\mathrm{T}$ cells can activate monocytes through CD40-CD40L interplay to enhance their expression of major histocompatibility complex class II (MHC II), inducible nitric oxide (iNOS), and TNF (49). In fact, the T helper 2 $\left(\mathrm{T}_{\mathrm{H}} 2\right)$ cells, dominating in the TME, activate macrophages to be polarized toward M2 macrophages, which promotes the development of immune suppression (50). Numerous studies have shown that TAMs can directly or indirectly inhibit $\mathrm{T}$ cell immune response through different mechanisms. The direct mechanisms include TAMs expressing inhibitory receptors to negatively regulate the activation of $\mathrm{T}$ cells by interaction with CD94 (51), expressing $\mathrm{T}$ cell immune checkpoint ligands to inhibit $\mathrm{T}$ cell functions $(52,53)$, producing cytokines to maintain a immunosuppressive microenvironment through inducing $\mathrm{T}_{\text {reg }}$ cell expansion and inhibiting $\mathrm{CD}^{+}$and $\mathrm{CD} 8^{+} \mathrm{T}$ cells $(54,55)$, and depleting L-arginine and tryptophan to inhibit cytotoxic $\mathrm{T}$ cells $(56,57)$. The indirect mechanisms include TAMs regulating the release of chemokines to control the recruitment of $\mathrm{T}_{\text {reg }}$ cells $(58,59)$, and blunting $\mathrm{T}$ cell recruitment by regulating the extracellular matrix (ECM) (60). 

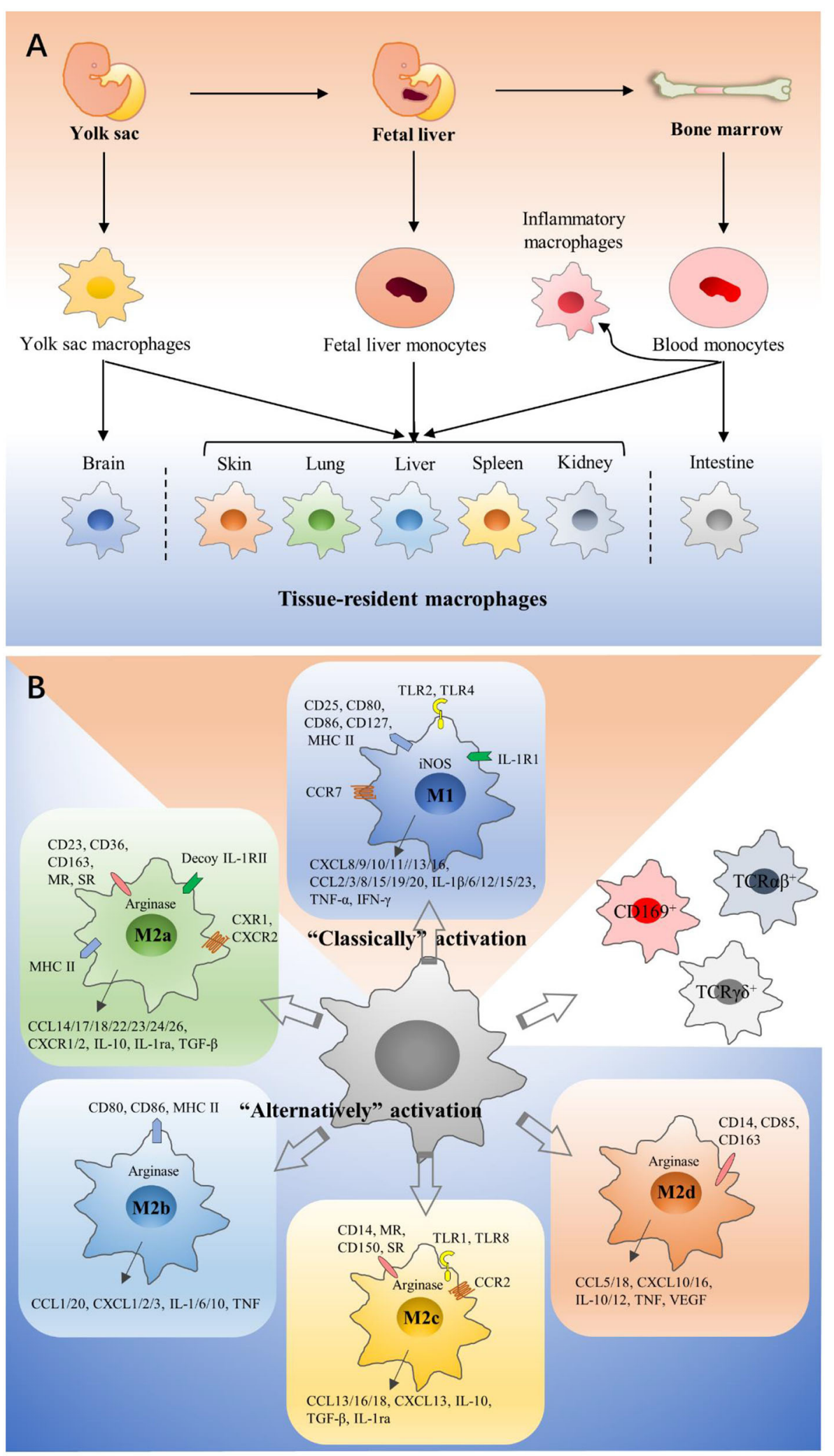

FIGURE 1 | Origins and polarization of macrophages. (A) Macrophages can have three different developmental pathways: fetal yolk sac, fetal liver, and bone marrow. Precursors seed different tissues and differentiate into specialized tissue-resident macrophages on the basis of tissue-specific context, and they have dramatical 
FIGURE 1 | differences in their phenotypes and functions. In tumors, TAMs are usually thought to primarily derive from circulating monocytes. (B) According to activation methods, macrophages are divided into M1 and M2 macrophages. M1 macrophages are polarized by LPS, which binds to TLR4. M2a macrophages are induced by IL-4 and IL-13. M2b macrophages are polarized by immune complexes and some TLR ligands. M2c macrophages would increase in the presence of IL-10 or glucocorticoids. M2d macrophages are induced by TLR agonists and adenosine. They have significant differences in surface receptor expression, metabolism, cytokine, and chemokine production. CD169+ macrophages, TCR $\alpha \beta^{+}$, and TCR $\gamma \delta^{+}$macrophages are classified into neither M1 macrophages nor M2 macrophages.

\section{Promoting Invasion and Metastasis}

Cancer metastasis is a complicated event, which plays a crucial role in the cause of morbidity and mortality $(61,62)$. It is worth noting that macrophages play an important role in tumor cells invasion and metastasis. They facilitate the escape of tumor cells from the basement membrane through the dense stroma by producing proteases to promote ECM degradation (63). Furthermore, several factors, such as macrophage-colony stimulating factor (M-CSF/CSF-1), can stimulate macrophages to promote tumor invasion $(64,65)$. Metastasis-associated macrophages (MAMs), a unique population of macrophages, have been identified are found to be recruited by CC chemokine ligand (CCL) $2(66,67)$. MAMs promote cancer cell invasion and metastasis by FMS-like tyrosine kinase 1 (FLT1) receptor tyrosine kinase signaling in a mouse model of breast cancer (68). In addition, several studies show that the activation of the CCL2/CC chemokine receptor (CCR) 2 axis is very important in MAMmediated metastasis $(66,67,69)$. Recent studies have shown that pre-metastatic niche (PMN) is a pre-requisite in mediating tumor cell metastasis. Primary tumor cells are thought to initiate the formation of PMN by the secretion of proinflammatory cytokines, chemokines, and angiogenic factors that recruit BMderived cells into future metastatic sites, and these cells induce PMN formation in reverse (70). For example, CXCL1 secreted by TAMs was reported to recruit CXCR2 ${ }^{+}$myeloid suppressor cells to promote liver PMN formation $(71,72)$.

\section{Promoting Angiogenesis}

Angiogenesis is necessary for tumor growth and metastasis, which is regarded as a "hallmark" of cancer (73). Accumulating evidence emphasizes the crucial roles of macrophages in promoting tumor angiogenesis, and TAMs is closely related to the number of blood vessels in the tumor (74). Hypoxia is the primary driver of angiogenesis, and some studies show that anoxic areas of tumors, especially the necrotic tissue, have large numbers of macrophages due to the releasing of endothelins, vascular endothelial growth factor (VEGF), high mobility group 1, CCL2, CXC chemokine ligand 8 (CXCL8), CXCL12, and CSF-1 (75). The increased expression of hypoxia-inducible transcription factors on TAMs up-regulates the transcription of various genes in hypoxic tumor sites, which responds to hypoxia and promotes tumor cells proliferation, metabolism, and angiogenesis (75-77). In a CSF-1 knockout mice model, macrophage number was found to significantly reduce in the tumor site, accompanied by impaired vascular development (78). In addition, tumor endothelium-released angiopoietin-2 (TIE-2) was reported to play an significant role in tumor angiogenesis by recruiting monocytes that express the TIE- 2 receptor (79). Furthermore, results of gene analysis indicated that TAMs could up-regulate the expression of various factors, which participate in tumor angiogenesis and provide nutrients for tumor growth (39).

\section{IMMUNOTHERAPY-TARGETING TAMS IN CANCER}

\section{Restoration of Macrophage Phagocytosis}

CD47 has been found expressed on many tumor cells, and it can bind with signal regulatory protein $\alpha$ (SIRP $\alpha)$ on the membrane surface of macrophages, which down-regulates macrophage phagocytosis of tumor cells $(80,81)$. In the past few years, a number of clinical trials have been conducted to determine various treatments that block CD47/SIRP $\alpha$ (Figure 2) (82). AntiCD47 antibody treatment could inhibit tumor growth in a pediatric brain malignancies model (83). Anti-CD47 antibody in combination with TTI-621, a SIRP $\alpha$-Fc fusion protein that could block the binding between SIRP $\alpha$ and CD47, promotes phagocytosis of tumor cells in s B-cell lymphoma mouse model (84). Hu5F9-G4, a human monoclonal antibody directing against $\mathrm{CD} 47$ has been tested in a tumor therapy as a single agent, as well as in combination with cetuximab. Nevertheless, antiCD47 therapies may increase the occurrence of transient anemia, because HSCs and red blood cells extensively express CD47 (85, 86). Furthermore, there are other “don't eat me" signals including programmed cell death ligand 1 (PD-L1), MHC 1 component $\beta 2$ microglobulin, and $\mathrm{CD} 24$, and antibodies which direct against the interaction of these signals with their macrophage surface receptors have demonstrated therapeutic potential in several cancers (87-89).

\section{Inhibition of Macrophage Recruitment}

Under tumor microenvironment, monocytes are rapidly recruited into tumor (90). Chemokines CCL2, CCL3, CCL4 and cytokines IL- $1 \beta$, and CSF-1 have proven to contribute to the monocyte recruitment into tumors $(91,92)$. It is shown that CCL2 expression is up-regulated by macrophages and tumor cells in TME (93-95). Moreover, the high expression of CCL2 has a correlation with the poor prognosis in many human and murine tumors (96). CCL2 promotes monocytes recruitment by stimulating CCR2. In fact, blocking CCL2/CCR2 not only inhibits the monocyte infiltration but also prevents immunosuppressive polarization of macrophages (97, 98). Currently, a number of treatments targeting CCL2/CCR2 are in clinical trials (99) (Figure 2). A CCR2 inhibitor, PF04136309, has been demonstrated to effectively inhibit tumor growth in pancreatic cancer patients $(100,101)$. CCL2 antibody treatment has proven to suppress tumor metastasis in a breast cancer model (96). Moreover, IL-1 $\beta$ has been identified as a chemoattractant target for cancer treatment. An IL-1 receptor antibody has been demonstrated to suppress inflammatory 


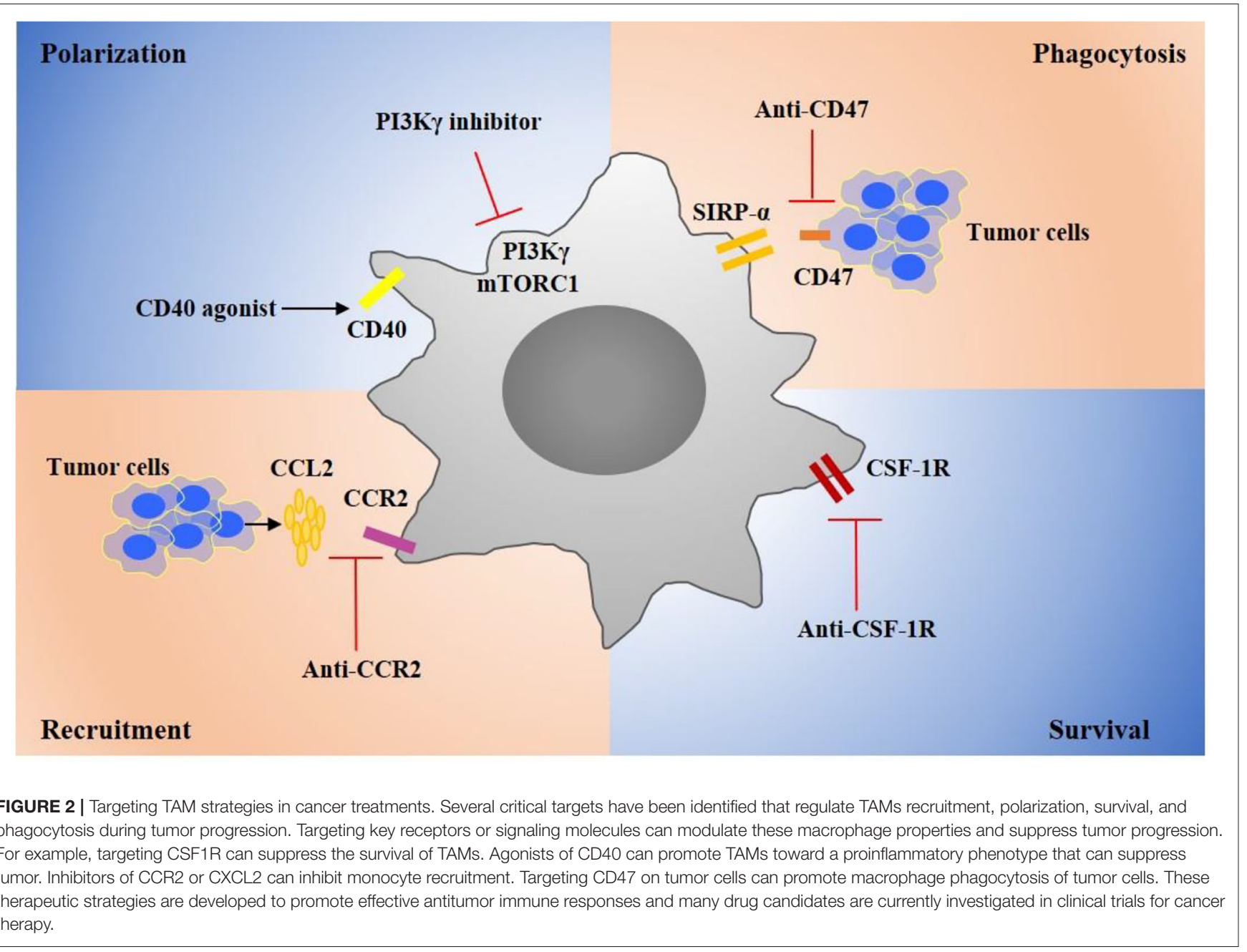

macrophage accumulation and tumor growth in lung and breast cancer mouse models (100). Moreover, in combination with fluorouracil and bevacizumab, Anakinra, an IL-1 receptor antibody, has been shown to prolong patients' life in a colorectal carcinoma Phase II clinical trial (102) (Table 1).

\section{Controlling Macrophage Proliferation and Survival}

CSF-1 receptor (CSF-1R), a tyrosine kinase receptor, plays a key role in regulating macrophage proliferation and survival (103). Several studies show that blocking CSF-1/CSF-1R inhibited immunosuppressive macrophage polarization, reduced tumor cell proliferation, and promoted apoptosis, therefore suppressing tumor progression and prolonged life survival (104, 105) (Figure 2). M279, a CSF-1R antibody, blocking both CSF-1 and IL-34, has been shown to inhibit tumor growth and improve survival rate in a spontaneous breast tumor model $(106,107)$. BLZ945, a small-molecule CSF-1R inhibitor has been reported to be therapeutically effective in glioma and breast cancer mouse models (108). Moreover, a number of CSF-1R-specific inhibitors, including PLX3397, PLX7486, and BLZ945, have been tested in clinical trials $(109,110)$. Especially, PLX3397, exhibiting higher affinity to CSF-1R, has demonstrated a better effect for tenosynovial giant cell tumor therapy, and the drug has been advanced into clinical trial phase III (111). In addition, several FDA-approved tyrosine kinase inhibitors, such as targeting c-KIT and VEGFR, have also been shown to have a binding activity with the CSF-1R kinase (112).

\section{Modulation of Macrophage Phenotype}

PI-3 kinase $\gamma(\mathrm{PI} 3 \mathrm{~K} \gamma)$ has been identified as a promising target for modulating macrophage phenotype and proinflammatory cytokine expression (113) (Figure 2). IPI-549, a PI3K $\gamma$ inhibitor, is currently tested in Phase $1 \mathrm{~b}$ clinical trials for several solid tumors, in combination with nivolumab. Bruton's tyrosine kinase (BTK), a downstream of PI3K $\gamma$, has been investigated as a target for cancer treatment. In line with studies, ibrutinib, a BTK inhibitor, has been advanced in Phase III clinical trials for pancreatic adenocarcinoma treatment and in Phase II clinical trials for relapsed or refractory solid tumor therapy in combination with durvalumab. Janus kinase 2 (JAK2) and STAT3 also have been regarded as potential targets for macrophage 
TABLE 1 | Clinical trials of macrophage-targeting agents.

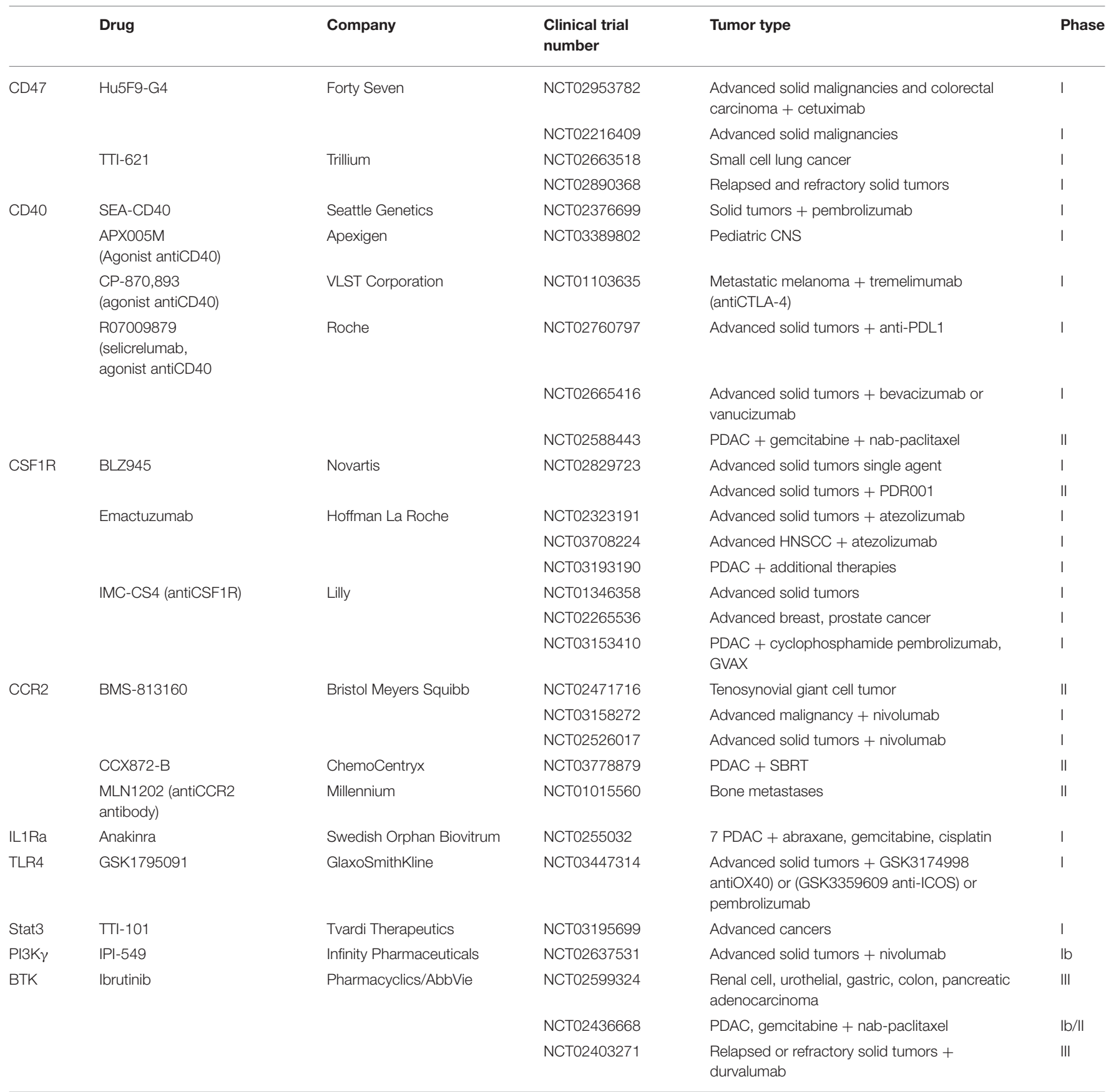

repolarization (114). The STAT3 inhibitor TTI-101 is currently investigated in a Phase I clinical trial for advanced cancers, and the JAK2 inhibitor has been applied for the treatment of psoriasis, myelofibrosis, and rheumatoid arthritis in clinic (115).

CD40 is mainly expressed on antigen presenting cells, monocytes, and some tumor cells. CD40 ligation in macrophages induces secretion of proinflammatory cytokines and promotes macrophage polarization toward a proinflammatory macrophage. Several anti-CD40 antibodies and CD40 ligands, such as RO7009789, APX005M, are currently under test and evaluation in clinical trials for solid tumors (Figure 2). Interestingly, unlikely other activatory Fc receptors, the antibody Fc domain with inhibitory Fc $\gamma$ RIIb is required for anti-40 antibody because of its agonistic immunostimulatory activity. In particular, CP-870893, a Pfizer anti-CD40 antibody of IgG2 subclass, has been shown to be more competitive in immunostimulation compared to other drugs in clinical trials (116). Moreover, TLR agonist treatment has been studied and 
developed for cancer therapy because TLRs stimulation can polarize macrophages toward a proinflammatory phenotype.

\section{Metabolic Modulation of TAMs}

To support specialized cellular activities, macrophages use diverse metabolic pathways for energy and metabolite at different states (117). Metabolic changes contribute to the regulation of macrophage polarization, and TAMs display an immunosuppressive phenotype that is defined by the production of ornithine and polyamines through the arginase pathway as well as by expression of $\mathrm{T}_{\mathrm{H}} 2$ cytokines that include IL-10 (118-120). Several studies have shown that the tumor microenvironment, featured poor nutrient and acidic environment, directly induced macrophages to adopt immunosuppressive phenotypes (121-123). For example, lactate, a byproduct of tumor cells, can promote monocytes and macrophages toward to immunosuppressive macrophage polarization in B16 melanoma and lung carcinomas mouse model (121). Moreover, the tumor microenvironment in melanomas characterized by acid has been reported to promote immunosuppressive polarization of TAMs, including upregulating arginase and VEGF expression (124). Collectively, these studies have shown that altering the metabolic pathways of TAMs to repolarize macrophages might be an effective strategy for antitumor functions.

The PI3K/Akt/mTOR myeloid signaling pathway plays a key role in regulation of TAMs metabolism by promoting L-arginine metabolism, a curial section that could promote immunosuppression. The gene and protein expression of Arginase-1 (Arg-1) in TAMs up-regulates and inhibition of PI3K $\gamma$ can suppress Arg-1 expression and activity (90). Additionally, the deletion of $\mathrm{PI} 3 \mathrm{~K} \gamma$ promotes the expression of the enzyme NOS, which promotes the production of the free radical and NO to function as anti-tumor. Kaneda et al. reported that IPI-549, a PI3k $\gamma$ inhibitor, inhibited lung carcinoma and breast tumors by promoting TAM-immunostimulatory response (125). Moreover, mTORC1 and mTORC2 also play a key role in the metabolic programming of macrophages by sensing nutrients, oxygen, and metabolites. Rapamycin, an mTORC1 inhibitor, has been reported to promote macrophages toward the proinflammatory phenotype with an anti-tumor effect (126) (Figure 2).

\section{Adoptive Macrophages Transfer}

Adoptive cell transfer is an emerging method of immunotherapy, which kills and removes cancer cells by the infusion of immune cells (127). Macrophages have the capacity to penetrate tumors (128), which may kill tumor cells where CAR-T therapy has fallen (129). Therefore, adoptive macrophage transfer (AMT) has become a hot research field for tumor detection and treatment lately. Amin Aalipour et al. used engineered macrophages as diagnostic sensors to successfully detect tumors as small as $4 \mathrm{~mm}$ in diameter and show better sensitivity than traditional cancer biomarkers (130). Recently, Michael Klichinsky et al. described an anti-HER2 CAR-macrophage
(CAR-M) that significantly reduced metastatic tumor burden (131). A cellular IFN- $\gamma$ "backpack" for macrophages was reported to promote phagocytosis and polarize macrophages toward the M1 phenotype, which further slows down the tumor growth in a murine breast cancer model (132). Overall, the adoptive transfer therapy of macrophages is still in the research stage, and there are many problems to be solved, such as the establishment of pre-clinical models to evaluate the efficacy and safety of AMT. In addition, the way to efficiently transfer genes into human macrophages is still challenging and needs further study.

\section{DISCUSSION}

Various strategies targeting TAMs have been studied for cancer therapy, and some treatments have been advanced into clinical trials. However, because of complexity of tumors, a combination therapy is usually adopted to maximize the anti-tumor effect; whether currently targeted signaling pathways therapeutically overlap or synergize in vivo remains to be explored. More importantly, current researches do not have a thorough understanding of these targets, and their other functions are often overlooked in cancer treatment. Besides, with multiple targets being identified and drugs being tested for the modulation of TAMs, drug delivery technologies have been advanced to further enhance the efficacy of these drugs, through the way of improving stability, selectivity, and intracellular delivery efficiency, etc. CAR-M, as an emerging strategy for cancer therapeutic, is still in research stage. Currently, overcoming the challenge that genes transfer into human macrophages and finding effective solid tumor targets are the main tasks. Perhaps CAR-M in the future is to adopt multiple macrophages having different functions rather than a single population.

TAMs represent a heterogeneous population with different functions according to different origins and contexts. Consequently, it is necessary to understand this heterogeneity and how it evolves during the progression of cancer and also following therapy in human, not mouse, models. In this context, the extensive use of single-cell RNA sequencing, multiplex immunohistochemistry, and mass cytometry will considerably increase our knowledge about TAMs, which is essential for the adoption of precision medicine and good prediction of patient responses. Admittedly, many questions remain regarding to properties and functions of macrophages in TME. However, with the deeper understanding of macrophage diversity through single-cell sequencing and other technologies, we believe that TAM-targeted treatment will be an important addition for cancer immunotherapy.

\section{AUTHOR CONTRIBUTIONS}

YL conceived the concept and wrote the manuscript. RW edited and improved the manuscript. All authors contributed to the article and approved the submitted version. 


\section{REFERENCES}

1. Bray F, Ferlay J, Soerjomataram I, Siegel RL, Torre LA, Jemal A. Global cancer statistics 2018: GLOBOCAN estimates of incidence and mortality worldwide for 36 cancers in 185 countries. CA Cancer J Clin. (2018) 68:394-424. doi: $10.3322 /$ caac. 21492

2. Togashi Y, Shitara K, Nishikawa H. Regulatory $T$ cells in cancer immunosuppression-implications for anticancer therapy. Nat Rev Clin Oncol. (2019) 16:356-71. doi: 10.1038/s41571-019-0175-7

3. Wu L, Saxena S, Awaji M, Singh RK. Tumor-associated neutrophils in cancer: going pro. Cancers. (2019) 11:564. doi: 10.3390/cancers11040564

4. Gorzalczany Y, Sagi-Eisenberg R. Role of mast cell-derived adenosine in cancer. Int J Mol Sci. (2019) 20:2603. doi: 10.3390/ijms20102603

5. Morvan MG, Lanier LL. NK cells and cancer: you can teach innate cells new tricks. Nat Rev Cancer. (2016) 16:7-19. doi: 10.1038/nrc.2015.5

6. Hume DA, The mononuclear phagocyte system. Curr Opin Immunol. (2006) 18:49-53. doi: 10.1016/j.coi.2005.11.008

7. Cooper MD, Alder MN. The evolution of adaptive immune systems. Cell. (2006) 124:815-22. doi: 10.1016/j.cell.2006.02.001

8. Epelman S, Lavine KJ, Beaudin AE, Sojka DK, Carrero JA, Calderon B, et al. Embryonic and adult-derived resident cardiac macrophages are maintained through distinct mechanisms at steady state and during inflammation. Immunity. (2014) 40:91-104. doi: 10.1016/j.immuni.2013.11.019

9. Epelman S, Lavine KJ, Randolph GJ. Origin and functions of tissue macrophages. Immunity. (2014) 41:21-35. doi: 10.1016/j.immuni.2014.06.013

10. Hoeffel G, Ginhoux F. Fetal monocytes and the origins of tissue-resident macrophages. Cell Immunol. (2018) 330:5-15. doi: 10.1016/j.cellimm.2018.01.001

11. Bian Z, Gong Y, Huang T, Lee CZW, Bian L, Bai Z, et al. Deciphering human macrophage development at single-cell resolution. Nature. (2020) 582:571-6. doi: 10.1038/s41586-020-2316-7

12. Locati M, Curtale G, Mantovani A. Diversity, mechanisms, and significance of macrophage plasticity. Annu Rev Pathol. (2020) 15:123-47. doi: 10.1146/annurev-pathmechdis-012418-012718

13. Ginhoux F, Guilliams M. Tissue-resident macrophage ontogeny and homeostasis. Immunity. (2016) 44:439-49. doi: 10.1016/j.immuni.2016.02.024

14. Mass E, Ballesteros I, Farlik M, Halbritter F, Gunther P, Crozet L, et al. Specification of tissue-resident macrophages during organogenesis. Science. (2016) 353:aaf4238. doi: 10.1126/science.aaf4238

15. Yona S, Kim K-W, Wolf Y, Mildner A, Varol D, Breker M, et al. Fate mapping reveals origins and dynamics of monocytes and tissue macrophages under homeostasis. Immunity. (2013) 38:1073-9. doi: 10.1016/j.immuni.2013.05.008

16. Ginhoux F, Greter M, Leboeuf M, Nandi S, See P, Gokhan S, et al. Fate mapping analysis reveals that adult microglia derive from primitive macrophages. Science. (2010) 330:841-5. doi: 10.1126/science.1194637

17. Martin E, El-Behi M, Fontaine B, Delarasse C. Analysis of microglia and monocyte-derived macrophages from the central nervous system by flow cytometry. J Vis Exp. (2017) 55781. doi: 10.3791/55781

18. Loyher PL, Hamon P, Laviron M, Meghraoui-Kheddar A, Goncalves E, Deng $\mathrm{Z}$, et al. Macrophages of distinct origins contribute to tumor development in the lung. J Exp Med. (2018) 215:2536-53. doi: 10.1084/jem.20180534

19. Chen Z, Feng X, Herting CJ, Garcia VA, Nie K, Pong WW, et al. Cellular and molecular identity of tumor-associated macrophages in glioblastoma. Cancer Res. (2017) 77:2266-78. doi: 10.1158/0008-5472.CAN-16-2310

20. Bowman RL, Klemm F, Akkari L, Pyonteck SM, Sevenich L, Quail $\mathrm{DF}$, et al. Macrophage ontogeny underlies differences in tumorspecific education in brain malignancies. Cell Rep. (2016) 17:2445-59. doi: 10.1016/j.celrep.2016.10.052

21. Okabe Y, Medzhitov R. Tissue-specific signals control reversible program of localization and functional polarization of macrophages. Cell. (2014) 157:832-44. doi: 10.1016/j.cell.2014.04.016

22. Stout RD, Jiang C, Matta B, Tietzel I, Watkins SK, Suttles J. Macrophages sequentially change their functional phenotype in response to changes in microenvironmental influences. J Immunol. (2005) 175:342-9. doi: $10.4049 /$ jimmunol.175.1.342
23. Shapouri-Moghaddam A, Mohammadian S, Vazini H, Taghadosi M, Esmaeili SA, Mardani F, et al. Macrophage plasticity, polarization, and function in health and disease. J Cell Physiol. (2018) 233:6425-40. doi: $10.1002 /$ jcp. 26429

24. Kawai T, Akira S. The role of pattern-recognition receptors in innate immunity: update on toll-like receptors. Nat Immunol. (2010) 11:373-84. doi: $10.1038 /$ ni. 1863

25. Malyshev I, Malyshev Y. Current concept and update of the macrophage plasticity concept: intracellular mechanisms of reprogramming and M3 macrophage "Switch" phenotype. Biomed Res Int. (2015) 2015:341308. doi: $10.1155 / 2015 / 341308$

26. Van Dyken SJ, Locksley RM. Interleukin-4- and interleukin13-mediated alternatively activated macrophages: roles in homeostasis and disease. Annu Rev Immunol. (2013) 31:317-43. doi: 10.1146/annurev-immunol-032712-095906

27. Vergadi E, Ieronymaki E, Lyroni K, Vaporidi K, Tsatsanis C. Akt signaling pathway in macrophage activation and M1/M2 polarization. J Immunol. (2017) 198:1006-14. doi: 10.4049/jimmunol.1601515

28. Herrmann I, Gotovina J, Fazekas-Singer J, Fischer MB, Hufnagl K, Bianchini $\mathrm{R}$, et al. Canine macrophages can like human macrophages be in vitro activated toward the M2a subtype relevant in allergy. Dev Comp Immunol. (2018) 82:118-27. doi: 10.1016/j.dci.2018.01.005

29. Yang R, Liao Y, Wang L, He P, Hu Y, Yuan D, et al. Exosomes derived from M2b macrophages attenuate DSS-induced colitis. Front Immunol. (2019) 10:2346. doi: 10.3389/fimmu.2019.02346

30. Murray PJ, Allen JE, Biswas SK, Fisher EA, Gilroy DW, Goerdt S, et al. Macrophage activation and polarization: nomenclature and experimental guidelines. Immunity. (2014) 41:14-20. doi: 10.1016/j.immuni.2014.06.008

31. Wang Q, Ni H, Lan L, Wei X, Xiang R, Wang Y. Fra-1 protooncogene regulates IL-6 expression in macrophages and promotes the generation of M2d macrophages. Cell Res. (2010) 20:701-12. doi: 10.1038/cr.2010.52

32. Poh AR, Ernst M. Targeting macrophages in cancer: from bench to bedside. Front Oncol. (2018) 8:49. doi: 10.3389/fonc.2018.00049

33. Maccio A, Gramignano G, Cherchi MC, Tanca L, Melis L, Madeddu C. Role of M1-polarized tumor-associated macrophages in the prognosis of advanced ovarian cancer patients. Sci Rep. (2020) 10:6096. doi: 10.1038/s41598-020-63276-1

34. Edin S, Wikberg ML, Dahlin AM, Rutegard J, Oberg A, Oldenborg PA, et al. The distribution of macrophages with a M1 or M2 phenotype in relation to prognosis and the molecular characteristics of colorectal cancer. PLoS ONE. (2012) 7:e47045. doi: 10.1371/journal.pone.0047045

35. An Y, Yang Q. MiR-21 modulates the polarization of macrophages and increases the effects of M2 macrophages on promoting the chemoresistance of ovarian cancer. Life Sci. (2020) 242:117162. doi: 10.1016/j.lfs.2019.117162

36. Caux C, Ramos RN, Prendergast GC, Bendriss-Vermare N, Menetrier-Caux C. A milestone review on how macrophages affect tumor growth. Cancer Res. (2016) 76:6439-42. doi: 10.1158/0008-5472.CAN-16-2631

37. Chavez-Galan L, Olleros ML, Vesin D, Garcia I. Much more than M1 and M2 macrophages, there are also CD169(+) and TCR $(+)$ macrophages. Front Immunol. (2015) 6:263. doi: 10.3389/fimmu.2015.00263

38. Chow A, Huggins M, Ahmed J, Hashimoto D, Lucas D, Kunisaki Y, et al. CD169(+) macrophages provide a niche promoting erythropoiesis under homeostasis and stress. Nat Med. (2013) 19:429-36. doi: 10.1038/nm.3057

39. Qian BZ, Pollard JW. Macrophage diversity enhances tumor progression and metastasis. Cell. (2010) 141:39-51. doi: 10.1016/j.cell.2010.03.014

40. Hussain SP, Harris CC. Inflammation and cancer: an ancient link with novel potentials. Int J Cancer. (2007) 121:2373-80. doi: 10.1002/ijc.23173

41. Cassetta L, Pollard JW. Targeting macrophages: therapeutic approaches in cancer. Nat Rev Drug Discov. (2018) 17:887-904. doi: 10.1038/nrd.2018.169

42. Canli O, Nicolas AM, Gupta J, Finkelmeier F, Goncharova O, Pesic M, et al. Myeloid cell-derived reactive oxygen species induce epithelial mutagenesis. Cancer Cell. (2017) 32:869-83.e5. doi: 10.1016/j.ccell.2017.11.004

43. Crusz SM, Balkwill FR. Inflammation and cancer: advances and new agents. Nat Rev Clin Oncol. (2015) 12:584-96. doi: 10.1038/nrclinonc.2015.105

44. Grivennikov SI, Wang K, Mucida D, Stewart CA, Schnabl B, Jauch $\mathrm{D}$, et al. Adenoma-linked barrier defects and microbial products drive IL-23/IL-17-mediated tumour growth. Nature. (2012) 491:254-8. doi: $10.1038 /$ nature 11465 
45. Greten FR, Karin M. The IKK/NF-kappaB activation pathway-a target for prevention and treatment of cancer. Cancer Lett. (2004) 206:193-9. doi: 10.1016/j.canlet.2003.08.029

46. Kong L, Zhou Y, Bu H, Lv T, Shi Y, Yang J. Deletion of interleukin-6 in monocytes/macrophages suppresses the initiation of hepatocellular carcinoma in mice. J Exp Clin Cancer Res. (2016) 35:131. doi: 10.1186/s13046-016-0412-1

47. Yang L, Dong Y, Li Y, Wang D, Liu S, Wang D, et al. IL-10 derived from M2 macrophage promotes cancer stemness via JAK1/STAT1/NFkappaB/Notch1 pathway in non-small cell lung cancer. Int J Cancer. (2019) 145:1099-110. doi: 10.1002/ijc.32151

48. Biswas SK, Mantovani A. Macrophage plasticity and interaction with lymphocyte subsets: cancer as a paradigm. Nat Immunol. (2010) 11:889-96. doi: $10.1038 /$ ni. 1937

49. Marigo I, Zilio S, Desantis G, Mlecnik B, Agnellini AHR, Ugel S, et al. T cell cancer therapy requires CD40-CD40L activation of tumor necrosis factor and inducible nitric-oxide-synthase-producing dendritic cells. Cancer Cell. (2016) 30:377-90. doi: 10.1016/j.ccell.2016.08.004

50. Pollard JW. Trophic macrophages in development and disease. Nat Rev Immunol. (2009) 9:259-70. doi: 10.1038/nri2528

51. Morandi F, Pistoia V. Interactions between HLA-G and HLA-E in physiological and pathological conditions. Front Immunol. (2014) 5:394. doi: 10.3389/fimmu.2014.00394

52. Buchbinder EI, Desai A. CTLA-4 and PD-1 pathways: similarities, differences, and implications of their inhibition. Am J Clin Oncol. (2016) 39:98-106. doi: 10.1097/COC.0000000000000239

53. Lin H, Wei S, Hurt EM, Green MD, Zhao L, Vatan L, et al. Host expression of PD-L1 determines efficacy of PD-L1 pathway blockade-mediated tumor regression. J Clin Invest. (2018) 128:805-15. doi: 10.1172/JCI96113

54. Ruffell B, Chang-Strachan D, Chan V, Rosenbusch A, Ho CM, Pryer $\mathrm{N}$, et al. Macrophage IL-10 blocks $\mathrm{CD}^{+} \mathrm{T}$ cell-dependent responses to chemotherapy by suppressing IL-12 expression in intratumoral dendritic cells. Cancer Cell. (2014) 26:623-37. doi: 10.1016/j.ccell.2014.09.006

55. Tauriello DVF, Palomo-Ponce S, Stork D, Berenguer-Llergo A, BadiaRamentol J, Iglesias $M$, et al. TGFbeta drives immune evasion in genetically reconstituted colon cancer metastasis. Nature. (2018) 554:538-43. doi: 10.1038/nature25492

56. Mbongue JC, Nicholas DA, Torrez TW, Kim NS, Firek AF, Langridge $\mathrm{WH}$. The role of indoleamine 2, 3-dioxygenase in immune suppression and autoimmunity. Vaccines. (2015) 3:703-29. doi: 10.3390/vaccines3030703

57. Gabrilovich DI, Nagaraj S. Myeloid-derived suppressor cells as regulators of the immune system. Nat Rev Immunol. (2009) 9:162-74. doi: $10.1038 /$ nri2506

58. Molon B, Ugel S, Del Pozzo F, Soldani C, Zilio S, Avella D, et al. Chemokine nitration prevents intratumoral infiltration of antigen-specific T cells. J Exp Med. (2011) 208:1949-62. doi: 10.1084/jem.20101956

59. Noy R, Pollard JW. Tumor-associated macrophages: from mechanisms to therapy. Immunity. (2014) 41:49-61. doi: 10.1016/j.immuni.2014.06.010

60. Ruffell B, Coussens LM. Macrophages and therapeutic resistance in cancer. Cancer Cell. (2015) 27:462-72. doi: 10.1016/j.ccell.2015.02.015

61. Seyfried TNH, Leanne C. On the origin of cancer metastasis. Crit Rev Oncog. (2013) 18:43-73. doi: 10.1615/CritRevOncog.v18.i1-2.40

62. Wells A, Grahovac J, Wheeler S, Ma B, Lauffenburger D. Targeting tumor cell motility as a strategy against invasion and metastasis. Trends Pharmacol Sci. (2013) 34:283-9. doi: 10.1016/j.tips.2013.03.001

63. Kessenbrock K, Plaks V, Werb Z. Matrix metalloproteinases: regulators of the tumor microenvironment. Cell. (2010) 141:52-67. doi: 10.1016/j.cell.2010.03.015

64. Wyckoff JB, Wang Y, Lin EY, Li JF, Goswami S, Stanley ER, et al. Direct visualization of macrophage-assisted tumor cell intravasation in mammary tumors. Cancer Res. (2007) 67:2649-56. doi: 10.1158/0008-5472.CAN-06-1823

65. Pukrop TK, Hagemann F, Gradl T, Schulz D, Siemes M, Trumper S, et al. Wnt $5 \mathrm{a}$ signaling is critical for macrophage-induced invasion of breast cancer cell lines. Proc Natl Acad Sci USA. (2006) 103:5454-9. doi: 10.1073/pnas.0509703103

66. Kitamura T, Qian BZ, Soong D, Cassetta L, Noy R, Sugano G, et al. CCL2-induced chemokine cascade promotes breast cancer metastasis by enhancing retention of metastasis-associated macrophages. J Exp Med. (2015) 212:1043-59. doi: 10.1084/jem.20141836

67. Qian B, Deng Y, Im JH, Muschel RJ, Zou Y, Li J, et al. A distinct macrophage population mediates metastatic breast cancer cell extravasation, establishment and growth. PLoS ONE. (2009) 4:e6562. doi: 10.1371/journal.pone.0006562

68. Qian BZ, Zhang H, Li J, He T, Yeo EJ, Soong DY, et al. FLT1 signaling in metastasis-associated macrophages activates an inflammatory signature that promotes breast cancer metastasis. J Exp Med. (2015) 212:1433-48. doi: 10.1084/jem.20141555

69. Kitamura T, Doughty-Shenton D, Cassetta L, Fragkogianni S, Brownlie D, Kato Y, et al. Monocytes differentiate to immune suppressive precursors of metastasis-associated macrophages in mouse models of metastatic breast cancer. Front Immunol. (2017) 8:2004. doi: 10.3389/fimmu.2017.02004

70. Erler JT, Bennewith KL, Cox TR, Lang G, Bird D, Koong A, et al. Hypoxia-induced lysyl oxidase is a critical mediator of bone marrow cell recruitment to form the premetastatic niche. Cancer Cell. (2009) 15:35-44. doi: 10.1016/j.ccr.2008.11.012

71. Zheng Y, Wang N, Wang S, Yang B, Situ H, Zhong L, et al. XIAOPI formula inhibits the pre-metastatic niche formation in breast cancer via suppressing TAMs/CXCL1 signaling. Cell Commun Signal. (2020) 18:48. doi: 10.1186/s12964-020-0520-6

72. Wang D, Sun H, Wei J, Cen B, DuBois RN. CXCL1 is critical for premetastatic niche formation and metastasis in colorectal cancer. Cancer Res. (2017) 77:3655-65. doi: 10.1158/0008-5472.CAN-16-3199

73. Hanahan D, Weinberg RA. Hallmarks of cancer: the next generation. Cell. (2011) 144:646-74. doi: 10.1016/j.cell.2011.02.013

74. Valkovic T, Dobrila F, Melato M, Sasso F, Rizzardi C, Jonjic N. Correlation between vascular endothelial growth factor, angiogenesis, and tumorassociated macrophages in invasive ductal breast carcinoma. Virchows Arch. (2002) 440:583-8. doi: 10.1007/s004280100458

75. Murdoch C, Muthana M, Coffelt SB, Lewis CE. The role of myeloid cells in the promotion of tumour angiogenesis. Nat Rev Cancer. (2008) 8:618-31. doi: $10.1038 / \mathrm{nrc} 2444$

76. Burke B. Expression of HIF-1 $\alpha$ by human macrophages: implications for the use of macrophages in hypoxia-regulated cancer gene therapy. J Pathol. (2002) 196:204-12. doi: 10.1002/path.1029

77. Murdoch C, Giannoudis A, Lewis CE. Mechanisms regulating the recruitment of macrophages into hypoxic areas of tumors and other ischemic tissues. Blood. (2004) 104:2224-34. doi: 10.1182/blood-2004-03-1109

78. Lin EY, Li JF, Gnatovskiy L, Deng Y, Zhu L, Grzesik DA, et al. Macrophages regulate the angiogenic switch in a mouse model of breast cancer. Cancer Res. (2006) 66:11238-46. doi: 10.1158/0008-5472.CAN-06-1278

79. Mazzieri R, Pucci F, Moi D, Zonari E, Ranghetti A, Berti A, et al. Targeting the ANG2/TIE2 axis inhibits tumor growth and metastasis by impairing angiogenesis and disabling rebounds of proangiogenic myeloid cells. Cancer Cell. (2011) 19:512-26. doi: 10.1016/j.ccr.2011.02.005

80. Zhao H, Wang J, Kong X, Li E, Liu Y, Du X, et al. CD47 promotes tumor invasion and metastasis in non-small cell lung cancer. Sci Rep. (2016) 6:29719. doi: 10.1038/srep29719

81. Jaiswal S, Jamieson CH, Pang WW, Park CY, Chao MP, Majeti R, et al. CD47 is upregulated on circulating hematopoietic stem cells and leukemia cells to avoid phagocytosis. Cell. (2009) 138:271-85. doi: 10.1016/j.cell.2009.05.046

82. Ngambenjawong C, Gustafson HH, Pun SH. Progress in tumor-associated macrophage (TAM)-targeted therapeutics. Adv Drug Deliv Rev. (2017) 114:206-21. doi: 10.1016/j.addr.2017.04.010

83. Gholamin S, Mitra SS, Feroze AH, Liu J, Kahn SA, Zhang M, et al. Disrupting the CD47-SIRPalpha anti-phagocytic axis by a humanized antiCD47 antibody is an efficacious treatment for malignant pediatric brain tumors. Sci Transl Med. (2017) 9:eaaf2968. doi: 10.1126/scitranslmed.aaf2968

84. Petrova PS, Viller NN, Wong M, Pang X, Lin GH, Dodge K, et al. TTI-621 (SIRPalphaFc): a CD47-blocking innate immune checkpoint inhibitor with broad antitumor activity and minimal erythrocyte binding. Clin Cancer Res. (2017) 23:1068-79. doi: 10.1158/1078-0432.CCR-16-1700

85. Liu J, Wang L, Zhao F, Tseng S, Narayanan C, Shura L, et al. Preclinical development of a humanized anti-CD47 antibody with anti-cancer therapeutic potential. PLoS ONE. (2015) 10:e137345. doi: 10.1371/journal.pone.0137345 
86. Ho CC, Guo N, Sockolosky JT, Ring AM, Weiskopf K, Ozkan E, et al. "Velcro" engineering of high affinity CD47 ectodomain as signal regulatory protein alpha (SIRPalpha) antagonists that enhance antibodydependent cellular phagocytosis. J Biol Chem. (2015) 290:12650-63. doi: 10.1074/jbc.M115.648220

87. Barkal AA, Weiskopf K, Kao KS, Gordon SR, Rosental B, Yiu YY, et al. Engagement of MHC class I by the inhibitory receptor LILRB1 suppresses macrophages and is a target of cancer immunotherapy. Nat Immunol. (2018) 19:76-84. doi: 10.1038/s41590-017-0004-z

88. Barkal AA, Brewer RE, Markovic M, Kowarsky M, Barkal SA, Zaro BW, et al. CD24 signalling through macrophage siglec-10 is a target for cancer immunotherapy. Nature. (2019) 572:392-6. doi: 10.1038/s41586-019-1456-0

89. O’Donnell JS, Long GV, Scolyer RA, Teng MW, Smyth MJ. Resistance to PD1/PDL1 checkpoint inhibition. Cancer Treat Rev. (2017) 52:71-81. doi: 10.1016/j.ctrv.2016.11.007

90. Kaneda MM, Cappello P, Nguyen AV, Ralainirina N, Hardamon $\mathrm{CR}$, Foubert $\mathrm{P}$, et al. Macrophage PI3Kgamma drives pancreatic ductal adenocarcinoma progression. Cancer Discov. (2016) 6:870-85. doi: 10.1158/2159-8290.CD-15-1346

91. Schmid MC, Franco I, Kang SW, Hirsch E, Quilliam LA, Varner JA. PI3kinase gamma promotes Rapla-mediated activation of myeloid cell integrin alpha4beta1, leading to tumor inflammation and growth. PLoS ONE. (2013) 8:e60226. doi: 10.1371/journal.pone.0060226

92. Lesokhin AM, Hohl TM, Kitano S, Cortez C, Hirschhorn-Cymerman D, Avogadri F, et al. Monocytic CCR2(+) myeloid-derived suppressor cells promote immune escape by limiting activated CD8 T-cell infiltration into the tumor microenvironment. Cancer Res. (2012) 72:876-86. doi: 10.1158/0008-5472.CAN-11-1792

93. Cai Z, Chen Q, Chen J, Lu Y, Xiao G, Wu Z, et al. Monocyte chemotactic protein 1 promotes lung cancer-induced bone resorptive lesions in vivo. Neoplasia. (2009) 11:228-36. doi: 10.1593/neo.81282

94. Lu Y, Cai Z, Galson DL, Xiao G, Liu Y, George DE, et al. Monocyte chemotactic protein-1 (MCP-1) acts as a paracrine and autocrine factor for prostate cancer growth and invasion. Prostate. (2006) 66:1311-8. doi: $10.1002 /$ pros.20464

95. Ueno T, Toi M, Saji H, Muta M, Bando H, Kuroi K, et al. Significance of macrophage chemoattractant protein-1 in macrophage recruitment, angiogenesis, and survival in human breast cancer. Clin Cancer Res. (2000) 6:3282-9.

96. Bonapace L, Coissieux MM, Wyckoff J, Mertz KD, Varga Z, Junt $\mathrm{T}$, et al. Cessation of CCL2 inhibition accelerates breast cancer metastasis by promoting angiogenesis. Nature. (2014) 515:130-3. doi: 10.1038/nature13862

97. Connolly KA, Belt BA, Figueroa NM, Murthy A, Patel A, Kim $\mathrm{M}$, et al. Increasing the efficacy of radiotherapy by modulating the CCR2/CCR5 chemokine axes. Oncotarget. (2016) 7:86522-35. doi: 10.18632/oncotarget.13287

98. Li X, Yao W, Yuan Y, Chen P, Li B, Li J, et al. Targeting of tumourinfiltrating macrophages via CCL2/CCR2 signalling as a therapeutic strategy against hepatocellular carcinoma. Gut. (2017) 66:157-67. doi: 10.1136/gutjnl-2015-310514

99. Lim SY, Yuzhalin AE, Gordon-Weeks AN, Muschel RJ. Targeting the CCL2CCR2 signaling axis in cancer metastasis. Oncotarget. (2016) 7:28697-710. doi: 10.18632/oncotarget.7376

100. Sanford DE, Belt BA, Panni RZ, Mayer A, Deshpande AD, Carpenter $\mathrm{D}$, et al. Inflammatory monocyte mobilization decreases patient survival in pancreatic cancer: a role for targeting the CCL2/CCR2 axis. Clin Cancer Res. (2013) 19:3404-15. doi: 10.1158/1078-0432.CCR13-0525

101. Nywening TM, Wang-Gillam A, Sanford DE, Belt BA, Panni RZ, Cusworth BM, et al. Targeting tumour-associated macrophages with CCR2 inhibition in combination with FOLFIRINOX in patients with borderline resectable and locally advanced pancreatic cancer: a single-centre, open-label, dosefinding, non-randomised, phase 1b trial. Lancet Oncol. (2016) 17:651-62. doi: 10.1016/S1470-2045(16)00078-4

102. Isambert N, Hervieu A, Rebe C, Hennequin A, Borg C, Zanetta S, et al. Fluorouracil and bevacizumab plus anakinra for patients with metastatic colorectal cancer refractory to standard therapies (IRAFU): a single-arm phase 2 study. Oncoimmunology. (2018) 7:e1474319. doi: 10.1080/2162402X.2018.1474319

103. Gao L, Wang FQ, Li HM, Yang JG, Ren JG, He KF, et al. CCL2/EGF positive feedback loop between cancer cells and macrophages promotes cell migration and invasion in head and neck squamous cell carcinoma. Oncotarget. (2016) 7:87037-51. doi: 10.18632/oncotarget.13523

104. Pyonteck SM, Akkari L, Schuhmacher AJ, Bowman RL, Sevenich L, Quail DF, et al. CSF-1R inhibition alters macrophage polarization and blocks glioma progression. Nat Med. (2013) 19:1264-72. doi: 10.1038/nm.3337

105. Yan D, Kowal J, Akkari L, Schuhmacher AJ, Huse JT, West BL, et al. Inhibition of colony stimulating factor-1 receptor abrogates microenvironmentmediated therapeutic resistance in gliomas. Oncogene. (2017) 36:6049-58. doi: 10.1038/onc.2017.261

106. Hume DA, MacDonald KP. Therapeutic applications of macrophage colonystimulating factor-1 (CSF-1) and antagonists of CSF-1 receptor (CSF-1R) signaling. Blood. (2012) 119:1810-20. doi: 10.1182/blood-2011-09-379214

107. Lohela M, Casbon AJ, Olow A, Bonham L, Branstetter D, Weng N, et al. Intravital imaging reveals distinct responses of depleting dynamic tumorassociated macrophage and dendritic cell subpopulations. Proc Natl Acad Sci USA. (2014) 111:E5086-95. doi: 10.1073/pnas.1419899111

108. Strachan DC, Ruffell B, Oei Y, Bissell MJ, Coussens LM, Pryer N, et al. CSF1R inhibition delays cervical and mammary tumor growth in murine models by attenuating the turnover of tumor-associated macrophages and enhancing infiltration by CD8(+) T cells. Oncoimmunology. (2013) 2:e26968. doi: 10.4161/onci.26968

109. Kogan M, Fischer-Smith T, Kaminsky R, Lehmicke G, Rappaport J. CSF$1 \mathrm{R}$ up-regulation is associated with response to pharmacotherapy targeting tyrosine kinase activity in AML cell lines. Anticancer Res. (2012) 32:893-9.

110. Brownlow N, Russell AE, Saravanapavan H, Wiesmann M, Murray JM, Manley PW, et al. Comparison of nilotinib and imatinib inhibition of FMS receptor signaling, macrophage production and osteoclastogenesis. Leukemia. (2008) 22:649-52. doi: 10.1038/sj.leu.2404944

111. Tap WD, Wainberg ZA, Anthony SP, Ibrahim PN, Zhang C, Healey JH, et al. Structure-guided blockade of CSF1R kinase in tenosynovial giant-cell tumor. N Engl J Med. (2015) 373:428-37. doi: 10.1056/NEJMoa1411366

112. Brownlow N, Mol C, Hayford C, Ghaem-Maghami S, Dibb NJ. Dasatinib is a potent inhibitor of tumour-associated macrophages, osteoclasts and the FMS receptor. Leukemia. (2009) 23:590-4. doi: 10.1038/leu.2008.237

113. De Henau O, Rausch M, Winkler D, Campesato LF, Liu C, Cymerman $\mathrm{DH}$, et al. Overcoming resistance to checkpoint blockade therapy by targeting PI3Kgamma in myeloid cells. Nature. (2016) 539:443-7. doi: $10.1038 /$ nature20554

114. Pathria P, Gotthardt D, Prchal-Murphy M, Putz EM, Holcmann M, Schlederer M, et al. Myeloid STAT3 promotes formation of colitisassociated colorectal cancer in mice. Oncoimmunology. (2015) 4:e998529. doi: 10.1080/2162402X.2014.998529

115. Ofengeim D, Yuan J. Regulation of RIP1 kinase signalling at the crossroads of inflammation and cell death. Nat Rev Mol Cell Biol. (2013) 14:727-36. doi: $10.1038 / \mathrm{nrm} 3683$

116. Vonderheide RH, Glennie MJ. Agonistic CD40 antibodies and cancer therapy. Clin Cancer Res. (2013) 19:1035-43. doi: 10.1158/1078-0432.CCR-12-2064

117. Ghesquiere B, Wong BW, Kuchnio A, Carmeliet P. Metabolism of stromal and immune cells in health and disease. Nature. (2014) 511:167-76. doi: 10.1038/nature13312

118. Covarrubias AJ, Aksoylar HI, Horng T. Control of macrophage metabolism and activation by mTOR and Akt signaling. Semin Immunol. (2015) 27:28696. doi: 10.1016/j.smim.2015.08.001

119. Huang SC, Smith AM, Everts B, Colonna M, Pearce EL, Schilling JD, et al. Metabolic reprogramming mediated by the mTORC2-IRF4 signaling axis is essential for macrophage alternative activation. Immunity. (2016) 45:817-30. doi: 10.1016/j.immuni.2016.09.016

120. Porta C, Sica A, Riboldi E. Tumor-associated myeloid cells: new understandings on their metabolic regulation and their influence in cancer immunotherapy. FEBS J. (2018) 285:717-33. doi: 10.1111/febs.14288

121. Colegio OR, Chu NQ, Szabo AL, Chu T, Rhebergen AM, Jairam V, et al. Functional polarization of tumour-associated macrophages by tumourderived lactic acid. Nature. (2014) 513:559-63. doi: 10.1038/nature13490 
122. Vitale I, Manic G, Coussens LM, Kroemer G, Galluzzi L. Macrophages and metabolism in the tumor microenvironment. Cell Metab. (2019) 30:36-50. doi: 10.1016/j.cmet.2019.06.001

123. Larionova I, Kazakova E, Patysheva M, Kzhyshkowska Transcriptional J. Epigenetic and metabolic programming of tumor-associated macrophages. Cancers. (2020) 12:1411. doi: 10.3390/cancers12061411

124. Kuchuk O, Tuccitto A, Citterio D, Huber V, Camisaschi C, Milione M, et al. $\mathrm{pH}$ regulators to target the tumor immune microenvironment in human hepatocellular carcinoma. Oncoimmunology. (2018) 7:e1445452. doi: 10.1080/2162402X.2018.1445452

125. Kaneda MM, Messer KS, Ralainirina N, Li H, Leem CJ, Gorjestani $S$, et al. PI3Kgamma is a molecular switch that controls immune suppression. Nature. (2016) 539:437-42. doi: 10.1038/nature 19834

126. Weichhart $T$, Hengstschlager $M$, Linke $M$. Regulation of innate immune cell function by mTOR. Nat Rev Immunol. (2015) 15:599-614. doi: $10.1038 /$ nri3901

127. Fefer A. Immunotherapy and chemotherapy of moloney sarcoma virusinduced tumors in mice. Cancer Res. (1969) 29:2177-83.

128. Ritchie D, Mileshkin L, Wall D, Bartholeyns J, Thompson M, Coverdale $\mathrm{J}$, et al. In vivo tracking of macrophage activated killer cells to sites of metastatic ovarian carcinoma. Cancer Immunol Immunother. (2007) 56:15563. doi: 10.1007/s00262-006-0181-3
129. Lee S, Kivimae S, Dolor A, Szoka FC. Macrophage-based cell therapies: the long and winding road. J Control Release. (2016) 240:527-40. doi: 10.1016/j.jconrel.2016.07.018

130. Aalipour A, Chuang HY, Murty S, D'Souza AL, Park SM, Gulati GS, et al. Engineered immune cells as highly sensitive cancer diagnostics. Nat Biotechnol. (2019) 37:531-9. doi: 10.1038/s41587-019-0064-8

131. Klichinsky M, Ruella M, Shestova O, Lu XM, Best A, Zeeman M, et al. Human chimeric antigen receptor macrophages for cancer immunotherapy. Nat Biotechnol. (2020) 38:947-53. doi: 10.1038/s41587-020-0462-y

132. Wyatt Shields C, IV, Evans MA, Wang LL-W, Baugh N, Iyer S, Wu D, et al. Cellular backpacks for macrophage immunotherapy. Sci Adv. (2020) 6:eaaz6579. doi: 10.1126/sciadv.aaz6579

Conflict of Interest: The authors declare that the research was conducted in the absence of any commercial or financial relationships that could be construed as a potential conflict of interest.

Copyright (c) 2020 Liu and Wang. This is an open-access article distributed under the terms of the Creative Commons Attribution License (CC BY). The use, distribution or reproduction in other forums is permitted, provided the original author(s) and the copyright owner(s) are credited and that the original publication in this journal is cited, in accordance with accepted academic practice. No use, distribution or reproduction is permitted which does not comply with these terms. 